\title{
Ceratocone: resultados visuais, complicações e qualidade de vida após ceratoplastia penetrante realizada por médico residente
}

\author{
Keratoconus: visual results, complications and life quality after penetrating \\ keratoplasty performed by a resident physician
}

\author{
Márcia Trovão Duarte Cavalcanti ${ }^{1}$ \\ Márcio Mahon² \\ Daniela Araújo Toscano da Nóbrega ${ }^{1}$ \\ Maria Cecília de Aguiar Remígio ${ }^{1}$ \\ Cecília Sales Pires ${ }^{1}$
}

\begin{tabular}{|l|}
\hline RESUMO \\
\hline Objetivo: Avaliar os resultados visuais, incidência de complicações e \\
qualidade de vida, utilizando-se o teste VF-14, dos pacientes submetidos \\
à ceratoplastia penetrante por ceratocone na Fundação Altino Ventura, \\
Recife(PE). Métodos: Quarenta e três pacientes submetidos à ceratoplastia \\
penetrante por ceratocone foram avaliados por meio do teste VF-14. O \\
tempo mínimo de seguimento foi de 18 meses. A média de idade dos \\
pacientes foi de 29,5 99,8 anos. Foram coletadas dos prontuários informa- \\
ções sobre os pacientes e seus respectivos exames oftalmológicos. Foi \\
utilizado o coeficiente de correlação de Pearson para análise de correlação \\
entre variáveis quantitativas. Aceitou-se r > 0,8 como indicativo de forte \\
correlação. Resultados: No último seguimento, 71,7\% dos pacientes \\
tinhamacuidade visual com correção (AVCC) maior ou igual a 0,5 . Entre as \\
complicações mais encontradas no pós-operatório estavam glaucoma \\
(26,1\%) e rejeição do enxerto (17,4\%). A pontuação final média do VF-14 \\
foi 78,7. As melhores pontuações obtidas foram para atividades como \\
dirigir durante o dia (100) e ler letras grandes (94), ao passo que as piores \\
pontuações foram para ler letras pequenas (79,8) e dirigir à noite (78,1). A \\
correlação entre as pontuações obtidas e a AV pós-transplante foi fraca \\
(r=0,46). Conclusões: Os resultados visuais forambons, uma vezque $71,7 \%$ \\
dos pacientes apresentaram AVCC $\geq 0,5$ no pós-operatório. Houve fraca \\
correlação entre a AV pós-transplante e a pontuação média do VF-14. A \\
incidência de complicações foi baixa, sendo a mais freqüente o glaucoma. \\
\hline
\end{tabular}

Descritores: Ceratocone; Ceratoplastia penetrante; Resultado de tratamento; Complicações pós-operatórias; Qualidade de vida

Departamento de Córnea da Fundação Altino Ventura com apoio do Hospital de Olhos de Pernambuco, em Recife - PE.

${ }^{1}$ Residente em Oftalmologia da Fundação Altino Ventura ${ }^{2}$ Staff do Departamento de Córnea da Fundação Altino Ventura e Hospital de Olhos de Pernambuco

Endereço para correspondência: FAV - Fundação Altino Ventura, Rua da Soledade, 170 - Recife (PE) CEP 50070-040

E-mail: fav@fundacaoaltinoventura.org.br

Recebido para publicação em 31.07.2003

Versão revisada recebida em 16.02.2004

Aprovação em 18.03.2004

\section{INTRODUÇ̃̃̃O}

O ceratocone é uma distrofia corneana progressiva e não-inflamatória com afinamento central, geralmente tratada com sucesso através do uso de lentes de contato. Entretanto, 10 a $20 \%$ dos pacientes, eventualmente, necessitam de ceratoplastia penetrante devido à cicatrização corneana em eixo visual, acuidade visual (AV) com correção com lentes de contato insuficiente ou intolerância ao uso das mesmas ${ }^{(1-2)}$.

O sucesso da ceratoplastia penetrante no ceratocone, que responde por aproximadamente um terço do total de indicações deste procedimento, está bem estabelecido, com alta taxa de sobrevivência do enxerto, melhora significativa da acuidade visual e baixa incidência de complicações ${ }^{(3-4)}$.
\end{abstract}


O fator qualidade de vida cada vez mais vem sendo reconhecido como um resultado que pode e deve ser mensurado em estudos dos efeitos da doença e seus respectivos tratamentos nos pacientes ${ }^{(5)}$.

O VF-14 é uma medida da capacidade funcional relacionada à visão, baseado em 14 atividades realizadas no dia a dia, que podem ser afetadas por doenças oculares ${ }^{(6-7)}$. Este teste também é válido na avaliação do resultado funcional visual após ceratoplastia penetrante ${ }^{(5)}$.

O objetivo deste estudo foi avaliar os resultados visuais, incidência de complicações e qualidade de vida, utilizando-se o teste VF-14, após ceratoplastias penetrantes por ceratocone realizadas na Fundação Altino Ventura (FAV).

\section{MÉTODOS}

Este estudo foi realizado no Departamento de Córnea da Fundação Altino Ventura, no período de agosto a novembro de 2002.

Para serem incluídos, os pacientes tinham de preencher os seguintes critérios: ter idade maior que 18 anos; história de ceratoplastia penetrante por ceratocone unilateral ou bilate$\mathrm{ral}$; ceratoplastia penetrante mais recente pelo menos $18 \mathrm{me}$ ses antes do início do estudo; presença de ambos os olhos; e ausência de deficiência mental ${ }^{(5)}$.

Os pacientes foram convidados a participar do estudo por telefone ou correspondência. Aqueles que desejaram participar, após assinatura do termo de consentimento livre e esclarecido, foram submetidos à entrevista pessoal, na qual se utilizou o teste VF-14, aplicado pelo mesmo pesquisador.

Questionou-se os pacientes quanto à dificuldade de realizar cada uma das 14 atividades dependentes da função visual avaliadas no VF-14. Quando o paciente indicava alguma dificuldade em realizar uma determinada atividade, ele era solicitado a graduar a dificuldade em uma escala de 4 estágios que variava de pouca dificuldade à incapacidade de realizá-la devido à visão. A pontuação de cada questão variou de 0 (incapaz de realizar) a 4 (sem dificuldade), sendo a pontuação final obtida pela multiplicação desta por 25 , cujo resultado variou de 0 (pior índice de função visual) a 100 (melhor índice de função visual) $)^{(5,8)}$.

Informações sobre os dados demográficos (idade e sexo) dos pacientes e dados relacionados aos períodos pré, per e pós-operatórios foram adquiridos nos prontuários médicos, utilizando-se um formulário padronizado no qual constavam acuidade visual pré e pós-operatória e complicações (incluiuse qualquer processo com potencial de comprometer o prognóstico visual).

As cirurgias foram realizadas por residentes do $3^{0}$ ano da Fundação Altino Ventura, supervisionados por um staff. O diâmetro do botão doador era de 0,25 a $0,50 \mathrm{~mm}$ maior do que $\mathrm{o}$ leito receptor, no qual era suturado com fio mononylon 10.0, com pontos interrompidos. No pós-operatório, as medicações utilizadas de rotina eram colírios de acetato de prednisolona a $1 \%$ e ofloxacina a $0,3 \%$. A dose do colírio esteróide era reduzida gradativamente dependendo da evolução ${ }^{(9)}$.

Foi utilizado o coeficiente de correlação de Pearson para análise de correlação entre variáveis contínuas. Aceitou-se o r > 0,8 como indicativo de forte correlação.

\section{RESULTADOS}

A amostra constou de 43 pacientes. Destes, vinte e cinco (58\%) eram do sexo masculino e 18 (42\%) do feminino. A média de idade foi de 29,5 $\pm 9,8$ anos, variando de 18 a 56 anos.

Foram analisadas 46 ceratoplastias penetrantes de 43 pacientes. Antes da cirurgia, 80,4\% dos pacientes tinham AV $\leq 0,2$, enquanto no pós-operatório mínimo de 18 meses, $71,7 \%$ deles tinham $\mathrm{AV} \leq 0,5$, com apenas 19,6\% com $\mathrm{AV} \leq 0,2$.

As complicações observadas no pós-operatório se encontram no gráfico 1 . Dos sete olhos que apresentaram rejeição, dois evoluíram com falência do enxerto e necessidade de um novo transplante. Glaucoma foi observado em dez olhos, que não apresentavam esta alteração no pré-operatório. $\mathrm{O}$ controle da pressão intra-ocular foi alcançado apenas com medicação antiglaucomatosa. Em quatro olhos, a pressão intra-ocular retornou aos níveis normais após a suspensão dos colírios esteróides.

Quanto à qualidade de vida, das 14 atividades avaliadas no VF-14 houve maior dificuldade para ler letras pequenas, dirigir veículos motorizados à noite e realizar trabalhos manuais. Dos 16 pacientes que referiram dirigir à noite, $56,2 \%$ apresentavam algum tipo de dificuldade. Quinze pacientes $(35,7 \%)$ tinham dificuldade para ler letras pequenas, enquanto treze $(30,2 \%)$ referiam dificuldade para realizar trabalhos manuais.

As melhores pontuações foram obtidas para dirigir veículos motorizados durante o dia ( $100 \%$ dos pacientes referiram não ter nenhuma dificuldade) e ler letras grandes (90,5\% não apresentavam dificuldades).

A distribuição das frequiências das respostas ao teste VF-

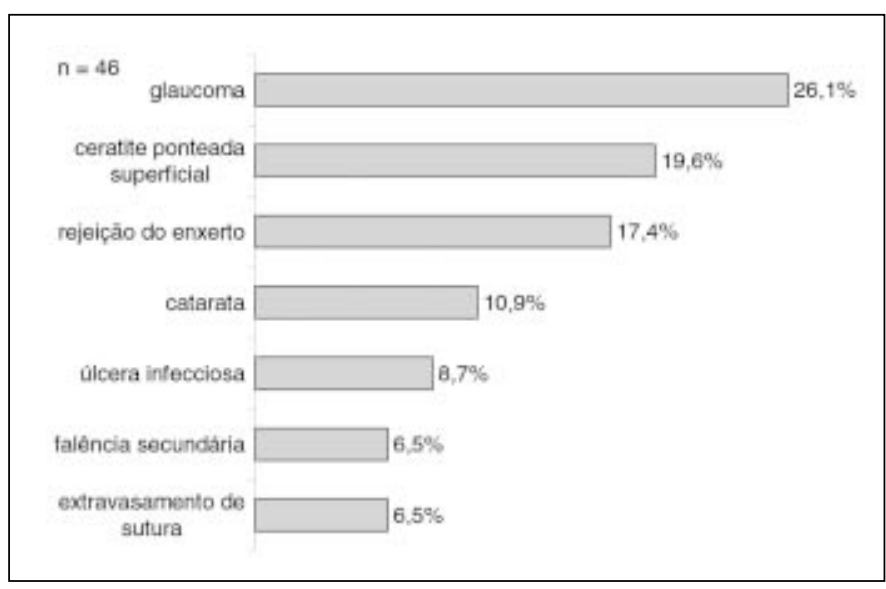

Gráfico 1 - Distribuição da freqüência de complicações das ceratoplastias penetrantes por ceratocone na FAV 
14 de acordo com o grau de dificuldade na realização das tarefas pesquisadas encontram-se na tabela 1 .

A correlação entre as pontuações obtidas e a AV póstransplante foi fraca (Coeficiente de correlação de Pearson $r=0,46 ; p=0,002$ ), como ilustra o gráfico 2 .

\section{DISCUSSÃO}

O ceratocone é a indicação mais freqüente $(23,9 \%)$ de ceratoplastia penetrante na Fundação Altino Ventura ${ }^{(9)}$. A amostra estudada constou de pacientes relativamente jovens, com média de idade de 29,5 $\pm 9,8$ anos, e houve discreta predominância masculina de 58\%, resultados semelhantes a estudos anteriores ${ }^{(1,4,9)}$.

As incidências de rejeição do enxerto são geralmente baixas nos pacientes com ceratocone. A freqüência de rejeição do enxerto de $17,4 \%$ neste estudo é similar às freqüências relatadas em estudos anteriores, que variavam de 7,8 a $31 \%{ }^{(1)}$.

O glaucoma pós-operatório foi a complicação mais freqüentemente encontrada no presente estudo, acometendo $26,1 \%$ dos olhos operados, incidência compatível com a literatura, onde variou de $10 \%$ a $34,1 \%{ }^{(2,4,9)}$. O uso de colírios esteróides pode ter contribuído no aumento da pressão intra-ocular em quatro olhos ${ }^{(4)}$.

A formação de catarata após este procedimento pode resultar do trauma cirúrgico, uma vez que as cirurgias foram realizadas por residentes, e do tratamento com esteróides no pós-operatório.

A incidência de úlcera infecciosa no pós-operatório, ocorrendo em $8,7 \%$ dos casos, foi alta em relação à literatura, na qual variou de $1,7 \%$ a $4,9 \%{ }^{(10)}$. Este fato deve-se provavelmente ao baixo poder aquisitivo da população em estudo, dificultando o acesso às medicações utilizadas no pós-operatório.

Uma série de fatores influencia na melhora da AV após ceratoplastia penetrante, entre eles a cicatrização corneana e a

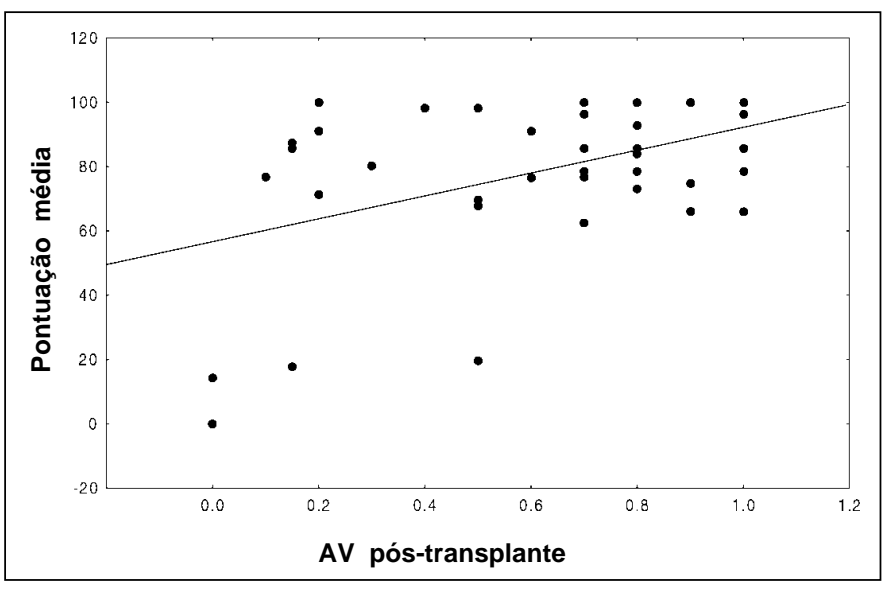

Gráfico 2 - Correlação entre as pontuações obtidas no VF-14 e a AV pós-transplante (Coeficiente de Pearson $r=0,46 ; p<0,01$ )

diminuição gradual do astigmatismo. A idade do receptor parece estar relacionada com a maneira com que isso ocorre em diferentes indivíduos, de modo que a cicatrização ocorre mais rapidamente quanto mais jovem for o paciente. Assim, o fator idade, associado à baixa incidência de fatores de morbidade ocular nos indivíduos mais jovens, pode contribuir significativamente para a importante melhora da $\mathrm{AV}$ nos pacientes com ceratocone $^{(11)}$.

Embora os resultados visuais sejam encorajadores, é importante também que se estabeleça se a ceratoplastia penetrante, acima de tudo, resultou em um benefício funcional para estes pacientes ${ }^{(4)}$. A restauração da transparência da córnea, ou de uma curvatura mais normal, nem sempre correspondem à melhora funcional nos receptores de enxertos de córnea. Em alguns casos, nem o resultado clínico nem a AV obtida estão de acordo com a satisfação e a expectativa do paciente ${ }^{(7)}$.

Foi usada uma medida da capacidade funcional visual, o VF-14, para mensurar a qualidade de vida dos pacientes da amostra estudada. As atividades da vida diária mais freqüen-

\begin{tabular}{|c|c|c|c|c|c|c|c|}
\hline Atividade & $\begin{array}{l}\text { Impossivel } \\
\text { realizar }\end{array}$ & $\begin{array}{l}\text { Dificuldade } \\
\text { intensa }\end{array}$ & $\begin{array}{l}\text { Dificuldade } \\
\text { moderada }\end{array}$ & $\begin{array}{l}\text { Dificuldade } \\
\text { mínima }\end{array}$ & $\begin{array}{c}\text { Sem } \\
\text { dificuldade }\end{array}$ & $\begin{array}{l}\text { Não se } \\
\text { aplicou }\end{array}$ & Média \\
\hline Ler jornal $(n=42)$ & $1(2,4 \%)$ & $3(7,2 \%)$ & $1(2,4 \%)$ & $8(19,0 \%)$ & $29(69,0 \%)$ & 1 & 86,3 \\
\hline Reconhecer pessoas $(n=43)$ & $2(4,6 \%)$ & 0 & $2(4,6 \%)$ & $1(2,4 \%)$ & $38(88,4 \%)$ & 0 & 92,4 \\
\hline Escadas $(n=42)$ & $1(2,4 \%)$ & $3(7,2 \%)$ & $1(2,4 \%)$ & $4(9,5 \%)$ & $33(78,5 \%)$ & 1 & 88,7 \\
\hline Sinais de trânsito $(n=43)$ & $4(9,3 \%)$ & 0 & $2(4,6 \%)$ & $5(11,7 \%)$ & $32(74,4 \%)$ & 0 & 85,5 \\
\hline Trabalhos manuais $(n=43)$ & $3(7,0 \%)$ & $2(4,6 \%)$ & $3(7,0 \%)$ & $5(11,7 \%)$ & $30(69,7 \%)$ & 0 & 83,1 \\
\hline Escrever $(n=42)$ & $1(2,4 \%)$ & $1(2,4 \%)$ & $2(4,8 \%)$ & $2(4,8 \%)$ & $36(85,6 \%)$ & 1 & 92,3 \\
\hline Jogar $(n=43)$ & $4(9,3 \%)$ & 0 & 0 & $1(2,3 \%)$ & $38(88,4 \%)$ & 0 & 90,1 \\
\hline Esportes $(n=36)$ & $3(8,3 \%)$ & $2(5,5 \%)$ & 0 & $2(5,5 \%)$ & $29(80,7 \%)$ & 7 & 86,1 \\
\hline Cozinhar $(n=43)$ & $1(2,3 \%)$ & $2(4,7 \%)$ & $1(2,3 \%)$ & $1(2,3 \%)$ & $38(88,4 \%)$ & 0 & 92,4 \\
\hline TV $(n=43)$ & $1(2,3 \%)$ & $4(9,3 \%)$ & $2(4,7 \%)$ & $4(9,3 \%)$ & $32(74,4 \%)$ & 0 & 86,0 \\
\hline Dirigir dia $(n=16)$ & 0 & 0 & 0 & 0 & $16(100 \%)$ & 27 & 100,0 \\
\hline Dirigir noite $(n=16)$ & 0 & 0 & $5(31,2 \%)$ & $4(25,0 \%)$ & $7(43,8 \%)$ & 27 & 78,1 \\
\hline Letras pequenas $(n=42)$ & $2(4,8 \%)$ & $4(9,5 \%)$ & $5(11,9 \%)$ & $4(9,5 \%)$ & $27(64,3 \%)$ & 1 & 79,8 \\
\hline Letras grandes $(n=42)$ & $1(2,4 \%)$ & 0 & $3(7,1 \%)$ & 0 & $38(90,5 \%)$ & 1 & 94,0 \\
\hline
\end{tabular}


temente prejudicadas pela visão neste estudo foram ler letras pequenas, dirigir à noite e realizar trabalhos manuais. A pontuação final média foi de 78,7, semelhante à encontrada no estudo de Musch et al. $(77)^{(5)}$ e superior à de Atique et al $(69,3)^{(8)}$. Apesar de $62,8 \%$ dos pacientes desse estudo não dirigirem veículos motorizados, a maioria $(97,7 \%)$ é alfabetizada e pratica algum tipo de esporte $(83,7 \%)$, o que facilitou a aplicação do questionário.

A fraca correlação entre as pontuações obtidas no teste VF-14 e as AV finais com melhor correção óptica provavelmente indica que não se pode estimar a qualidade de vida do paciente após a cirurgia a partir da acuidade visual.

\section{CONCLUSÕES}

Os resultados visuais foram bons, uma vez que $71,7 \%$ dos pacientes apresentaram AVCC $\geq 0,5$ no pós-operatório. Houve fraca correlação entre a AV pós-transplante e a pontuação média do VF-14. As complicações mais freqüentemente observadas foram glaucoma e ceratite ponteada superficial.

\section{AGRADECIMENTOS}

Ao professor Carlos Brandt pela orientação metodológica e ao professor Natal pela orientação na análise estatística.

\section{ABSTRACT}

Purpose: To evaluate the visual results, complication rates and life quality, using the VF-14 test, after penetrating keratoplasty for keratoconus, performed at the "Altino Ventura Foundation", Recife - Pernambuco, Brazil. Methods: Fortythree patients who underwent penetrating keratoplasty were evaluated by the VF-14 test. The mean age of the patients was $29.5 \pm 9.8$ years. The minimal follow-up was 18 months. The ophthalmological examination data were collected from their medical records. Pearson correlation coeficient was used to analyze the correlation between quantitative variants. $r<0.8$ was accepted as indicative of strong correlation. Results: At the last follow-up, $71.7 \%$ of the patients achieved 0.5 or better best corrected visual acuity (BCVA). Among the most com- mon complications in the postoperative phase were glaucoma $(26.1 \%)$ and graft rejection $(17.4 \%)$. The VF-14 final mean score was 78.7. Best scores were obtained in activities such as: car driving during the day (100) and reading large print material (94), while the worst scores were for reading small print material (79.8) and driving car at night (78.1). The correlation between the scores obtained and the VA after keratoplasty was weak $(r=0.46)$. Conclusions: The visual results were good, as $71,7 \%$ of patients presented BCVA $\geq 0.5$ in the postoperative phase. The correlation between VA after keratoplasty and mean score of VF-14 test was weak. The complications rates were low and glaucoma was the most frequent of them.

Keywords: Keratoconus/complications; Keratoplasty, penetrating; Treatment outcome; Postoperative complications; Quality of life

\section{REFERÊNCIAS}

1. Brierly SC, Izquierdo L Jr, Mannis MJ. Penetrating keratoplasty for keratoconus. Cornea 2000;19:329-32.

2. Tay KH, Chan WK. Penetrating keratoplasty for keratoconus. Ann Acad Med Singapore 1997;26:132-7.

3. Buzard KA, Fundingsland BR. Corneal transplant for keratoconus: results in early and late disease. J Cataract Refract Surg 1997;23:398-406.

4. Lim L, Pesudovs K, Coster DJ. Penetrating keratoplasty for keratoconus: visual outcome and success. Ophthalmology 2000;107:1125-31.

5. Musch DC, Farjo AA, Meyer RF, Waldo MN, Janz NK. Assessment of health - related quality of life after corneal transplantation. Am J Ophthalmol 1997;24:1-8.

6. Alonso J, Espallargues M, Andersen TF, Cassard SD, Dunn E, BernthPetersen $\mathrm{P}$ et al. International applicability of the VF-14. An index of visual function in patients with cataracts. Ophthalmology 1997;104:799-807.

7. Boisjoly H, Gresset J, Fontaine N, Charest M, Brunette I, Le François M et al. The VF-14 index of functional visual impairment in candidates for a corneal graft. Am J Ophthalmol 1999;128:38-44.

8. Atique D, Goulart DG, Lake JC, Lima FA, Felberg S, Nishiwaki-Dantas MC. Qualidade de vida após transplante penetrante de córnea. Arq Bras Oftalmol 2002;65:351-4.

9. Endriss D, Cunha F, Ribeiro MP. Ceratoplastias penetrantes realizadas na Fundação Altino Ventura: revisão dos resultados e complicações. In: V Encontro Científico dos Alunos do Curso de Especialização e Residência Médica em Oftalmologia; 2002 Jan 18-19, Recife, Brasil; 2002. p.151-60.

10. Santos NC, Sucomine PT, Sousa LB, Sato EH, Freitas D. Ceratite infecciosa pós-transplante de córnea. Arq Bras Oftalmol 1999;62:48-53.

11. Teixeira MF, Almeida Junior GC, Rodrigues ML, Kamimoto PS, Kashiwabuchi LK. Resultados e indicações de ceratoplastias penetrantes realizadas por médicos em treinamento, num país em desenvolvimento. Arq Bras Oftalmol 2001;64:557-61.

\section{ABO ELETRÔNICO}

\section{Novo site}

\section{Acesso: http://www.abonet.com.br}

